\title{
Contribution of Power Floating Muscle and Power Floating Arm Muscle on Smash Ability
}

\author{
Dova Syafriandi, Donie \\ Dep. Of Physical Education, \\ Faculty of Sport Science, \\ Universitas Negeri Padang \\ Padang, Indonesia \\ syafriandidova@gmail.com
}

\begin{abstract}
The purpose of this study was to study the contribution of limb muscle explosions and muscle explosive power to smash abilities of PB Semurup Junior badminton club athletes in Kerinci Regency, Jambi Province. This type of research is correlational. The population in this study were all PB Semurup Junior badminton club athletes in Kerinci Regency, Jambi Province, which supported 24 athletes. The sampling technique uses purposive sampling. Thus the sample in this study tested 18 male athletes. Data collection techniques are: 1) Explosion of limb muscles are tested with vertical jumps, 2) Explosive strength of the arm muscles is tested with two hand medicine balls, 3) Power of the smash is tested using a badminton court with money boxes that have been printed on the field. Data were analyzed correctly at the product and multiple conversions with a significant level of $\alpha=0.05$. The results of data analysis obtained are as follows: 1) Explosive strength of leg muscles contributes significantly to the smash ability of PB Semerup Junior badminton club athletes in Kerinci Regency Jambi Province by $37.82 \%$, 2) Explosive muscle strength of the arm contributes significantly to smash ability PB Semerup Junior badminton club athletes in Kerinci Regency Jambi Province amounted to $35.64 \%$, 3) Explosive strength of leg muscles and explosive strength of leg muscles together contributed significantly to smash ability of PB Semerup Junior badminton club athletes in Kerinci Regency, Jambi Province, 41, 34\%.
\end{abstract}

Keywords-Leg muscle explosive power, arm explosive muscle power, smash ability

\section{INTRODUCTION}

Badminton is one of the achievement sports that are fostered a lot, badminton is a popular sport among children, adolescents, and even parents are very fond of this sport. Lately, many badminton schools or clubs have been established in every district, region and city with the aim of finding new seeds of talented players to show achievements at both the national and international levels.

This badminton game is individualized that can be done individually by way of one on one or two people against two people. This game required tools in the form of a racket as a bat and a shuttlecock as a hit object, a rectangular badminton court and bounded by a net to separate the game area itself from the opponent's player area.

PB Semurup Junior Kerinci Regency is one of the clubs carrying out coaching in badminton. The purpose of this coaching is to get good achievements in the badminton branch, so that it can make the name of the region, as well as the name of the club in particular.

In coaching to achieve an achievement of playing badminton cannot be separated from the factors of physical ability, technical mastery and mental. This is in accordance with the opinion [1] that "The achievement achievement shown / displayed by an athlete in a competition is mainly determined and influenced by the ability or potential of the athlete himself in an integrated manner, both physical, technical, tactic, and mental abilities".

Badminton is a fast sport game and requires a good reaction and a good level of fitness. To be able to play badminton well, it is required to do a lot of practice, learn and understand physical, technical, tactic and mental elements. Because it might not be able to play well if the techniques that exist in the game of badminton are unknown and not understood.

In the game of badminton preparation for physical conditions is very important to improve and strengthen the quality of the technique. Physical condition is physical ability or the ability of one's body to work or exercise. Badminton basic technical skills are important to have for a player, because it is a picture of the skills he has. This means that the better the mastery in badminton, the higher the technical skill they have. The most dominant technique in the game of badminton is the stroke technique.

According [2], in general the technique of punches in badminton is: "1) Service, 2) Lob, 3) Chop, 4) Smash, 5) Drive and 7) Net shot". Smash is a blow from the top of the head that is hard, gliding power and steep downward, leading to the field of the opponent's field which can be used as a weapon to turn off the opponent's game or end the game to get numbers. Moreover, accompanied by a jump, the smash will be harder and faster because the body's swing when doing a bigger smash is issued so that the fall of the shuttlecock is harder and faster. According [3] "Smash is a key hit to turn off the shuttle cock on the side of the opponent, this blow is a finishing blow that shuttlecock is very difficult to return".

Based on the results of interviews with Club PB badminton coach Semurup Junior often took part in badminton training, but his achievements were not maximal, including in 2015 following the Regent Cup match between students, out of 7 student representatives no one could win, in 2015 following a level competition subdistrict of 10 students, only 2 people who won, in 2016 took part in the Anniversary match of Kerinci Regency, out of 9 students only one person won, in 2017 took part in a badminton match between junior high school students in Kerinci Regency, out of 10 only one student won the championship. It is thought that many factors influence the performance of PB Semurup Junior Club Badminton athletes in Kerinci 
Regency, including physical, technical, tactical and mental conditions.

Based on observations and observations made by the author in the field of the badminton athletes of PB PB Semurup Junior Kerinci, the authors see the player's smash ability is not good. This can be seen when doing a smash, the blows made by the player are not hard, not sharp and lacking direction so that the opponent easily returns the shuttlecock, this condition will certainly be advantageous for the opponent to get points. Many factors affect one's smash ability in badminton, one of which is suspected physical condition including, leg muscle explosive power, arm muscle explosive power, eye-hand coordination, waist flexibility, agility, speed.

In badminton the explosive power of the leg muscles is crucial to smash. Athletes who have good leg muscle explosive power can certainly do higher jumps, so the shuttle cock that is hit doesn't involve on the net. In badminton the explosive power of the arm muscles is crucial to smash. Players who have good arm muscle explosive power can certainly make a blow (smash) with a strong and hard, so that the shuttlecock is hard to be returned by the opponent.

In badminton games, especially when jumping smashes, eye-hand coordination is very important. Because the eye of an optical instrument that functions for vision and hands is an upper limb, these two parts of the body work together to achieve goals such as movements in jumping smashes. Because both are connected by the nervous system, the sharpness of the eye in seeing stimuli is like seeing the path of the shuttlecock.

Badminton requires good flexibility in order to move in all directions without injury. Badminton requires agility for fast movements and is followed by changes in direction, both forward right side net, front left side net, right side, left side, back side right and left. Badminton requires speed, especially for blows of attack speed and mobility of movement with egillitas that are usually used to close the field, or to chase shuttles in all directions.

Based on the description above, then on this occasion the author wants to conduct a study to get the actual data and information contribution of leg muscle explosive power and arm muscle explosive power to the badminton athlete's smash ability of the PB Semurup Junior Club in Kerinci Regency, Jambi Province.

The theories discussed in this study are:

1. Smash ability

According [4] "Smash is a quick blow, directed down strongly and sharply to return the short ball that has been hit up." According [2] "Smash is a key blow to turn off the opponent's game". Based on this understanding, it can be concluded that the ability of a smash is closely related to the ability, ability, someone to make a sharp smash and swoop down the fieldiness of the opponent and difficult to return the opponent

2. Leg muscle explosive power

According to Annarino in [5] explosive power is "Strength and speed of dynamically explosive muscle contractions in a fast time". In the badminton game explosive power (exploit power) is the ability of a very dominant physical condition where the movements in the smash are expolosive power blocks, namely the explosive power of the leg muscles

3. Arm muscle explosive power

According [2] explosive power is "the ability of a muscle or a group of muscles to overcome load resistance at high speed in an intact motion". Based on some of the opinions and explanations above, it can be concluded that the explosive power of the arm muscles is the ability of the arm muscles to direct force quickly in a short time to provide the best momentum for the object in a fully explosive movement to achieve the desired goal. The explosive power of the arm muscle in this study is the ability of the muscles to exert maximum force to make a smash, so the punch is hard and deadly.

\section{RESEARCH METHODOLOGY}

This type of research is correlational. The population in this study were all athletes of the PB Semurup Junior Badminton Club in Kerinci Regency, Jambi Province, totaling 24 athletes. The sampling technique uses purposive sampling. Thus the sample in this study amounted to 18 male athletes. Data collection techniques are: 1) Leg muscle explosive power was tested with a vertical jump, 2) Arm muscle explosive power was tested with two hand medicine ball put, 3) The ability to smash was tested using a badminton court with boxes $\neg$ values that have been printed in the field. Data were analyzed with product moment correlation and multiple correlation with a significant level $\alpha=0.05$.

\section{RESULTS}

\section{Leg muscle explosion power}

From 18 athletes, 1 person $(5.56 \%)$ athletes have arm muscle explosive power with very good classification, 4 people $(22.22 \%)$ athletes who have good leg muscle explosive power, 8 people $(44.44 \%)$ athletes have leg muscle explosive power with a moderate classification, 4 people $(22.22 \%)$ athletes have leg muscle explosive power with less classification and 1 person $(5.56 \%)$ athletes who have leg muscle explosive power with very less classification. For more detailed histogram distrubution frequency data on the explosive power of the athlete's leg muscles can be seen in Figure 1.

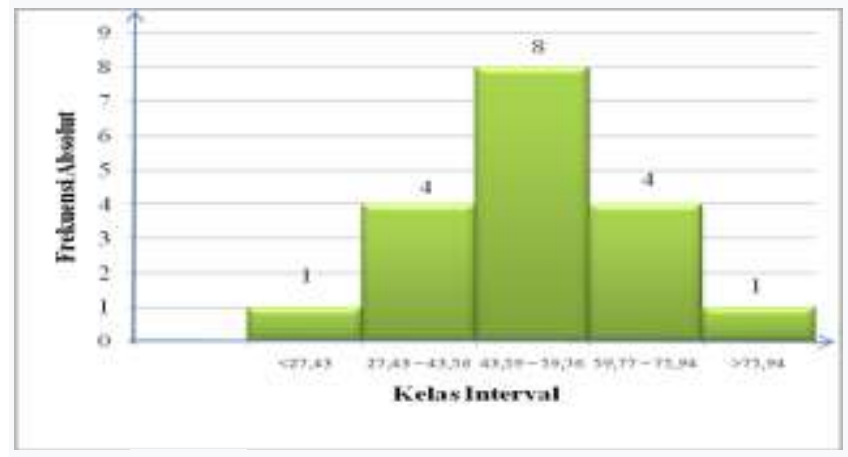

Figure 1 1. Histogram of Leg Muscle Power 


\section{Arm Muscle Power Explosion}

Of the 18 athletes, none of the athletes had arm muscle explosive power with very good and good classification, 4 people $(22.22 \%)$ athletes had arm muscle explosive power with moderate classification, 11 people $(61.11 \%)$ athletes had power explosive arm muscle with less classification and 3 people $(16.67 \%)$ athletes who have arm muscle explosive power with very little classification. For more details can be seen in Figure 2.

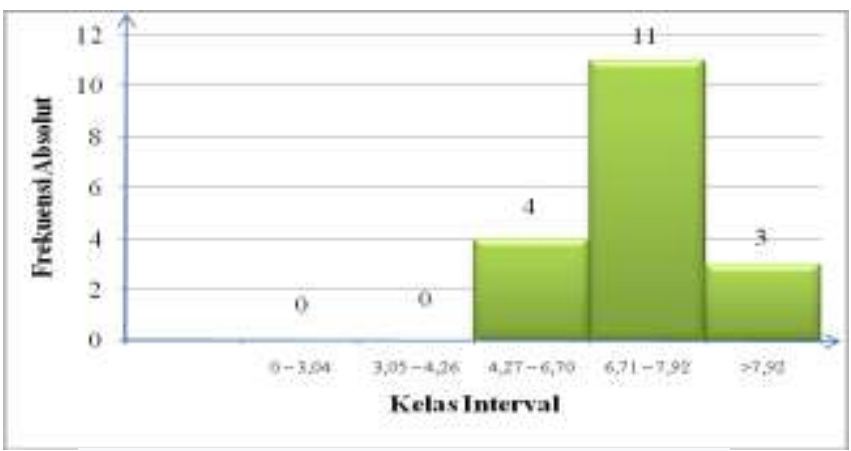

Figure 2. Histogram of Arm Muscle Explosion

\section{Smash ability}

From 18 athletes, 1 person $(5.56 \%)$ athletes who have a smash ability with a very good classification, 4 people $(22.22 \%)$ athletes who have a smash ability with a good classification, 7 people $(38.89 \%)$ athletes have a smash ability with moderate classification, 6 people $(33.33 \%)$ athletes had the ability to smash with less classification and none of the athletes had the ability to smash with very little classification. For more details on the frequency distribution histogram of the athlete's smash ability can be seen in Figure 3 .

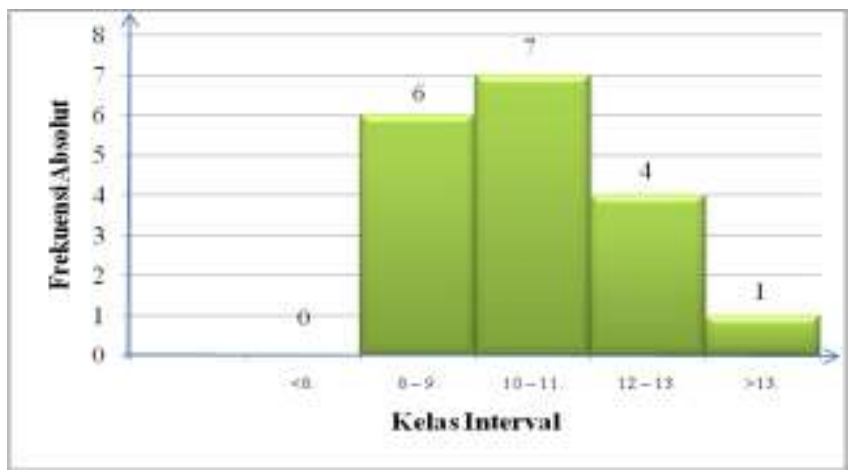

Figure 3. Data Histogram of Smash Ability

\section{DISCUSSION}

1. There is a significant relationship between leg muscle explosiveness and the ability to smash the badminton club athletes PB Semurup Junior, Kerinci Regency, Jambi Province

Based on the results of the correlation analysis between the leg muscle explosive power to the smash ability, it was obtained a count of $0.615>$ rtable 0.468 . To test the significant correlation coefficient between the leg muscle explosive power and the smash ability, a t test was performed. Based on the results of the $t$ test obtained $t$ count $=3.110>\mathrm{t}$ table 1.744 with. Thus it can be concluded that there is a significant (significant) relationship between leg muscle explosive power to the smash ability of PB Semurup Junior Badminton club athletes in Kerinci Regency, Jambi Province, and leg muscle explosive power contributing $37.82 \%$ to the smash ability.

Based on the results of the above study, it is clear that the leg muscle explosive power is related and contributes considerably to the smash ability of PB Semurup Junior badminton club athletes in Kerinci Regency, Jambi Province. Therefore, it is necessary to pay attention to the badminton club coach PB Semurup Junior, Kerinci Regency, Jambi Province to be able to increase the athlete's leg muscle explosive power, including providing leg muscle explosive power training with or without weights.

2. There is a contribution of arm muscle explosive power to the smash ability of PB Semurup Junior badminton club athletes in Kerinci Regency, Jambi Province

Based on the results of the correlation analysis between arm muscle explosive power to the ability to smash rcounts obtained 0.597> rtable 0.468 and $\mathrm{t}$ arithmetic $=2.987>\mathrm{t}$ table 1.746 with and contributed to the smash ability of $=$ $35.64 \%$. This means that the contribution of arm muscle explosive power to the smash ability of PB Semurup Junior Badminton Club athletes in Kerinci Regency, Jambi Province is $35.64 \%$. This means that the more explosive power of one's arm muscles, the better the smash ability.

According to Watson in [6] stated the explosive power is: "concerning the strength and speed of muscle contraction that is dynamic and explosive and involves the expenditure of maximum muscle strength in the shortest possible time". According to Bompa in [1] defines, "Explosive power as a product of two abilities, namely strength (strength) and speed (speed) to perform maximum force in a fast time".

The explosive power of the arm muscles is one of the basic components of physical condition which is very important in badminton, especially when doing smashes, both short and far smashes. if a player has no power good arm muscle burst when doing a smash, of course, the shuttlecock that is hit isn't strong and is easy for the opponent to return. Smash in badminton is a sharp downward punch at a hard speed. Smash referred to in this study is smsah done with all his strength so that the opponent cannot be returned.

From the description above, it is clear that for someone to be able to do a good smash then the physical condition element of arm muscle explosive power is very much needed. Because the ability of physical conditions, arm muscle explosive power is one aspect that will greatly affect the ability to smash, meaning when doing a smash that is supported by physical conditions. One of them is the explosive power of arm muscles.

Based on the results of the above study, it is clear that the arm muscle explosive power contributes quite significantly to the smash ability of PB Semurup Junior Badminton club athletes in Kerinci Regency, Jambi Province. This means that the better the arm muscle explosive power, the better the player's smash ability. Therefore, it is important to pay 
attention to the badminton club coach PB Semurup Junior, Kerinci Regency, Jambi Province to be able to increase the explosive power of the athlete's arm muscles.

In this way, to get good arm muscle explosive power, training is needed that can increase arm muscle explosive power, such as throwing and catching balls with medicine balls individually and in pairs,

3. There is a contribution of leg muscle explosive power and arm muscle explosive power together to the smash ability of badminton club athletes PB Semurup Junior Kerinci Regency of Jambi Province

Based on the results of the calculation of multiple correlations obtained $\mathrm{r}$ count $=0.643>\mathrm{r}$ table 0.468 and $\mathrm{F}$ test it turns out that $\mathrm{F}$ count $=5.29>\mathrm{F}$ table 3.68. Thus it can be concluded that there is a significant (significant) relationship between leg muscle explosive power and arm muscle explosive power together with the smash ability of badminton club athletes PB Semurup Junior Kerinci Regency of Jambi Province and contribute to the smash ability of $=41.34 \%$.

According [4] "Smash is a quick blow, directed down firmly and sharply to return the short ball that has been hit up". According [2] "Smash is a key blow to turn off the opponent's game".

Based on the above quote, it is clear that smash is a major blow to victory. To get a good smash ability certainly requires good physical condition, such as leg muscle explosive power and arm muscle explosive power. Athletes who have good leg muscle explosive power can certainly make higher jumps, so that they can direct the shuttlecock to the intended target area and the shuttlecock that is hit is unrelated on the net. The explosive power of the arm muscles has a function so that a strong and hard punch is created so that the ball cannot be returned if the opponent's party is well and can create points.

Based on the results of the study above, it is clear that the leg muscle explosive power and the inert muscle explosive power contribute significantly to the smash ability of PB Semurup badminton club athletes in Kerinci Regency, Jambi
Province. Therefore, the two factors mentioned above need to be trained and need to be considered, both from the coach and from the athlete itself. Thus efforts that can be made to improve the ability to smash need to be increased training in leg muscle explosive power and arm muscle explosive power in a programmed and continuous manner.

\section{CONCLUSION}

Based on the research results described in the previous chapter the conclusions can be concluded as follows:

1. Leg muscle explosive power contributed significantly to the smash ability of PB Semerup Junior badminton club athletes in Kerinci Regency, Jambi Province by $37.82 \%$.

2. Arm muscle explosive power contributed significantly to the smash ability of PB Semerup Junior badminton club athletes in Kerinci Regency, Jambi Province by $35.64 \%$.

3. Leg muscle explosive power and arm muscle explosive power together contributed significantly to the smash ability of PB Semerup Junior badminton club athletes in Kerinci Regency, Jambi Province by $41.34 \%$.

\section{REFERENCES}

[1] Syafruddin. "Sports Coaching Science". Padang: FIK UNP. UNP Press. 2011, pp. 31.

[2] Khairuddin. "Guidelines for Badminton Games". Padang: FIK UNP. 2000, pp. 55.

[3] Zarwan. "Badminton". Padang: Sukabina Press. 2012, pp. 25.

[4] Tony Grice. "Badminton: Practical Guidance for Beginners and Advanced". Jakarta: PT. Raja Grafindo Persada. 2004, pp. 45.

[5] Arsil. "Development of Physical Conditions". DIP State University of Padang. 1999, pp. 37.

[6] Ismaryati. “Tes Pengukuran”. Jakarta. 2006, pp. 67. 